\title{
Characteristics of body image as a structural component of subjective well-being
}

\author{
Anna Danilova* \\ Peoples' Friendship University of Russia, 117198, Moscow, Russia
}

\begin{abstract}
There have been many foreign studies verifying a robust link between body image and a person's subjective well-being. However, unlike their foreign counterparts, Russian researchers have been limiting themselves to covering general questions pertaining to a relation between a person's well-being and their body image. Thus, the coverage for the body image as a structural component of subjective well-being has been insufficient. The present study appears relevant given the need for a deeper understanding of mechanisms that maintain mental health in adolescent girls and the need for a deeper understanding of factors contributing to the formation of their subjective well-being. In the context of this paper we view the body image as a key component of a person's well-being. The present study surveyed female students of the Philological Faculty of the Peoples' Friendship University of Russia (RUDN). The sample included 100 (N=100) participants aged from 18 to 22 years, with the average age being 22 . We analyzed and compiled the theoretical studies on the subject of subjective well-being (SWB) and body image as well as their correlation, by both foreign and Russian researchers. We also compiled some empirical data on the subject of body image as a component of a person's well-being. Statistical methods such as the Spearman's rank-order correlation analysis and factor analysis were employed. The data suggested that the subjective perception of one's body image had a great influence on various structural components of one's personality.
\end{abstract}

\section{Introduction}

In the last three decades the body of research on subjective well-being has shown significant advancement. This is partly due to the fact that contemporary researchers go beyond the early cross-sectional studies of various external correlates of this phenomenon such as employment, gender, and culture and focus on the study of a wide range of internal determinants of subjective well-being, such as adaptation, extraversion, various personality traits, positive emotions [29], coping strategies, etc. [24, 25, 28].

A promising area of research in this area is the study of body image as a key internal determinant of a person's well-being. Modern society and culture propagate the idea that attractiveness is a requirement for success in life. This leads to increased demands being placed on women's appearance which leads to physical attractiveness becoming a major factor in one's perception of happiness. This greatly impacts young women's minds which easily accept the stereotypes regarding attractive appearance. At the same time, this imposed

* Corresponding author: info.danilova@gmail.com 
standard is very difficult to achieve for most of them, which in turn has an extremely negative impact on their subjective well-being.

Thus, a thorough conceptual and methodical analysis of the structural features of the body image and its impact on the structure of the self-perception in young women, allows us to reveal the factors pertaining to the formation of mechanisms of self-regulation, selfactualization and self-development, as well as improve the level of subjective well-being of women whose appearance does not correspond to the ideal adopted in their social environment.

The formation of one's subjective well-being is a very long process with many stages, the first being the development of the bodily awareness, and the last one being the definition of the meaning of one's life.

The period of adolescence plays a major role in this long process. The changes the body and the appearance undergo through puberty, the uncertain mental state resulting from being not quite a child and not quite an adult, as well as an increase in complexity of life's challenges all trigger a goal-oriented worldview, start the process of personal formation and growth, and lead to a change in one's hierarchy of needs. [1]

As per Erickson, the adolescence begins at the age of 19 and ends at the age of 35 [22] During this period, women take a special interest in their own personality, they seek to establish a family, and are generally more self-critical. At this stage, the act of self-reflection becomes more and more important. Their own thoughts, desires and aspirations become the subject of special attention and study. During this period, it becomes particularly important for women to stand out from their surroundings, to show their originality and dissimilarity to others. [20]

Adolescence is the apex of the spiritual and physical aspects of self, the period of moral, intellectual and mental maturity. In adolescence the body also reaches its mature state. [6]

The questions of sexuality become especially important, as puberty results in development of a certain range of sexual needs. Those needs are directed at men and, at the same time, at the woman's peers who find themselves in the same circumstances.

One of the key factors in one's subjective well-being is a rational self-esteem that is, in turn, defined by the woman's body and appearance. [30]

During the period of adolescence girls are prone to pay close attention to such elements of their appearance as height, body size, body weight, bodily proportions, even their haircut, and facial features, among others. Many of them develop a strong desire to change their appearance.

This happens as a result of the fact that their perception of their bodies lacks in objectivity and sometimes even directly contradicts the perception of people in their social environment.

Girls that develop feelings of body shame during adolescence are especially susceptible to this. Their desire to compare themselves to their peers compounded by a wide range of growth patterns in adolescents results in a drastic worsening in self-esteem and perception of self-worth. Physical characteristics play a major role in this process, since they become the basis of their self-identity, as well as the basis of social responses to their appearance and relations with the opposite sex. [27] The feedback from the social environment (such as approval, taunts, admiration) has a crucial impact on the formation of their self-image.

There are a multitude of factors preventing adolescent girls from feeling content with their bodies. According to H. Remschmidt, the majority of those is constituted by various irrational beliefs and attitudes.

Constant need for comparing oneself with one's peers results in girls developing anxiety and fears of inadequacy. [10] Even the smallest deviations from the perceived norm can lead to heightened anxiety, which invariably decreases the levels of one's well-being.

The most recent studies of this matter conclusively proved that girls are more sensitive to any deviations of their body image from the perceived norm. The studies' results stress the 
importance of viewing body image as a structural component of the subjective well-being in adolescent boys and girls.

There have been many studies confirming a robust link between the body image and a person's subjective well-being. [26, 23] However, there is virtually no research that deals with the structural features of body image as one of the key components of subjective wellbeing of young women.

The relevance of the present study is determined by the fact, that the vast majority of the existing body of research on the subject of subjective well-being is concerned with general questions about the relation between body image and well-being. The specific aspects of body image as a structural component of one's well-being remain understudied. The relevance of this topic is also determined by the need for a deeper understanding of the mechanisms for maintaining the mental health of adolescent girls and for a deeper understanding of the factors contributing to the formation of their sense of well-being.

The study aims to reveal the structural features of the body image as a component of the subjective well-being in adolescent girls.

The goals of the study are as follows:

1. To conduct a theoretical analysis of the body of research by both Russian and foreign scientists pertaining to the relation between body image and a person's subjective well-being.

2. To conduct an empirical study of the structural features of the body image in adolescent girls and the ways it influences various components of their self-concept.

3. To conduct an empirical study of adaptive strategies employed by girls with different attitudes towards their bodies.

The results show that the key hypothesis suggesting the existence of difference in wellbeing in young women with different level of satisfaction with their own bodies has proven to be correct. We also ascertained that the body image determined the self-concept and adaptive strategies used by the participants. The hypothesis regarding the participants from the 1st group utilizing more mature psychological mechanisms and being more capable of regulating their eating habits has also proven to be correct.

\section{Methodology}

The present study surveyed female students of the Philological Faculty of the Peoples' Friendship University of Russia. The sample included $100(\mathrm{~N}=100)$ participants aged from 18 to 22 years, with the average age being 22 . The questionnaire incorporated the following:

1) «Subjective Scaling» questionnaire by K.V. Ivanova [5]

2) Body image scale by Dean Jade [9]

3) «Interpretation of the elements of appearance» by V.A. Labunskaya and E.V. Belugina [2]

4) Questionnaire on body image by O.A. Skugarevsky and S.V. Sivukha [19]

5) Questionnaire on self-perception by V.V. Stolin and S.R. Pantiveyev [11]

6) Questionnaire on social frustration diagnostic by L.E. Vasserman (modified by V.V. Boiko) [12]

7) Evaluation of psychometric qualities by Plutchik-Kellerman-Konte (Life Style Index, LSI) [3]

8) The Dutch Eating Behavior Questionnaire (DEBQ). [8]

Primary data processing was done in the Statistical Package for the Social Sciences (SPSS 20.0).

In order to reveal the features of body image as a structural component of SWB in adolescent girls we used Spearman's rank-order correlation coefficient and factor analysis.

The main goal behind using the factor analysis was to determine the general correlation between subjective body image and other elements of the participants' self-concept. 
In order to further clarify the differences between two groups of participants with opposite body image perception we used factor analysis with Varimax rotation.

The first group included participants displaying above average bodily satisfaction. The second group included respondents displaying below average bodily satisfaction.

\section{Results and discussion}

The hypothesis we posed in the preliminary stages of the study stated that a positive body image - being an integral part of the SWB - had a negative correlation with such personal traits as despondency, guilt, and frustration.

We also postulated that scales characterizing such positive manifestations as selfunderstanding, self-respect, self-consistency, among others had a positive correlation with body image.

Table 1 showcases the data that supports the hypothesis

Table 1. Results of the correlation analysis

\begin{tabular}{|c|c|c|}
\hline Scale & $\begin{array}{l}\text { Spearman coefficient value } \\
\left(\mathrm{r}_{\mathrm{s}}\right)\end{array}$ & $\begin{array}{l}\text { Statistical significance } \\
\text { (p) }\end{array}$ \\
\hline Body image & 1 & $p=0.001$ \\
\hline Self-interest & 0.372 & $p=0.001$ \\
\hline Self-acceptance & 0.385 & $p=0.001$ \\
\hline Self-understanding & 0.352 & $p=0.001$ \\
\hline Self-respect & 0.501 & $\mathrm{p}=0.001$ \\
\hline Self-assurance & 0.498 & $\mathrm{p}=0.001$ \\
\hline Self-consistency & 0.330 & $p=0.001$ \\
\hline Autosympathy & 0.462 & $p=0.001$ \\
\hline $\begin{array}{l}\text { Perception of own } \\
\text { appearance }\end{array}$ of & 0.590 & $\mathrm{p}=0.001$ \\
\hline $\begin{array}{l}\text { General satisfaction with } \\
\text { own appearance }\end{array}$ & 0.519 & $\mathrm{p}=0.001$ \\
\hline $\begin{array}{l}\text { Subjective assessment of } \\
\text { own facial features }\end{array}$ & 0.715 & $\mathrm{p}=0.001$ \\
\hline Commitment to weight loss & 0.393 & $p=0.001$ \\
\hline $\begin{array}{l}\begin{array}{c}\text { Satisfaction with own } \\
\text { weight }\end{array} \\
\text { w }\end{array}$ & 0.328 & $\mathrm{p}=0.001$ \\
\hline $\begin{array}{c}\text { Reflected appearance } \\
\text { assessment }\end{array}$ & 0.672 & $\mathrm{p}=0.001$ \\
\hline Despondency & -0.372 & $p=0.001$ \\
\hline Guilt & -0.290 & $p=0.001$ \\
\hline Frustration & -0.295 & $p=0.001$ \\
\hline Hyper compensation & -0.222 & $\mathrm{p}=0.001$ \\
\hline
\end{tabular}

The data sheds light on some characteristics of the body image as a component of the SWB in adolescent girls.

As shown in Table 2, such personal characteristics as self-interest, self-acceptance, selfunderstanding, self-esteem, self-confidence, autosympathy, perception of own appearance, general satisfaction with own appearance, subjective perception of own facial features, and commitment to weight loss display a positive correlation with body image. This comes as no surprise, given that there have been studies showing similar results. $[21,4,7,18]$

The data suggests that girls with a more positive body image are more prone to selfreflection and self-study, including constant study of their inner self. The women of this category tend to have a better esteem of different elements of their appearance in particular, and their overall appearance in general. They highly rate such elements of appearance as 
facial features and body weight, which points to a detailed analysis of their strengths and weaknesses followed by acceptance. Genuine self-acceptance is the basis of constant selfimprovement and self-development.

With that said, a positive correlation between body image and commitment to weight loss indicates that such positive view of one's appearance is not baseless but comes as a result of concentrated efforts to optimize one's physical parameters, which lead to a higher satisfaction with one's appearance.

The abovementioned facts suggest that the participants with a positive body image display a more positive view of themselves, thus demonstrating a higher level of autosympathy, which, in turn, manifests not only as acceptance of one's appearance, but as specific behavior patterns, that are determined by individual's personal qualities and some other factors.

The positive correlation between autosympathy and body image indicates that girls satisfied with their bodies are prone to think highly of their appearance, but that doesn't result in baseless admiration of their bodies. On the contrary, their positive self-concept is evidence of a robust and sturdy foundation that supports their self-esteem.

Self-understanding manifests, in this case, in an ability to notice and recognize one's actions, along with conscious and suppressed intentions, feelings, and desires. The participants with a positive body image show a greater capacity to manage their life, adapt to changes in life's rhythms and, as a result, show a greater capacity to achieve meaningful goals.

It bears mentioning that girls with a relatively more positive body image are characterized by a higher dependence on others' opinions of them. In this regard we suppose that adolescent girls put much effort into meeting the external expectations and succeed in this effort. The positive correlation between the target parameter and reflected appearance scales comes as a direct proof of that.

In conclusion, based on the aforementioned data, we can reasonably assume that a positive body image as a structural component of SWB is characteristic of mature individuals with a profound ability to accept oneself as they are, while remaining cognizant of all one's flaws and edges.

Getting back to Table 2, we can trace a negative correlation between body image and such negative characteristics as despondency, guilt, and frustration. This signifies that the participants who were satisfied with their bodies have little inclinations towards sadness, bad moods and pessimism. They are unlikely to display irritation, anger, and anxiety when facing unmet needs.

This suggests that the participants with a positive body image are less likely to experience frequent depression with low physical activity, inertness, and lack of motivation. They maintain an optimistic outlook and remain in harmony with the world. Thus, in their everyday lives such women do not have much need to utilize a wide range of psychological defense mechanisms. This comes as a result of their refusal to disregard negative emotions by purposefully overlooking their causes.

A positive correlation between body image and hyper compensation prove the abovementioned conclusions, since such a defensive mechanism is more typical for socially mature individuals. In an attempt to overcome real or perceived defects one expends great effort, which not only gets rid of the feeling of inferiority, but often puts the person in a dominant position in relation to their social environment.

The factor analysis of the data from the first group revealed 4 factors of SWB, that consist of the indicators related to general self-perception and the indicators that determine the general intensity of the psychological defensive mechanisms.

The first factor consists solely of variables with positive factor weights:

General self-attitude (0.885)

Self-respect (0.708) 
Expected attitude from others $(0.635)$

Self-interest (0.557)

Self-consistency (0.511).

As the data shows this factor is made up of those scales that are related to high selfesteem. The self-esteem, in turn, is supported by a higher expected esteem from others in the immediate environment. Let's designate this factor as «positive self-attitude with positive expected attitude from others".

The second factor consists of the following variables:

General body image (0.844);

Body image (0.788);

Satisfaction with own weight (- 0.671);

Restrictive eating habits $(0.621)$;

Subjective view of own weight (- 0.536).

For this factor, we see a certain dissonance between the elements related to weight satisfaction and elements related to body image. This is likely due to the fact that this category of women is oriented towards certain ideal body standards and puts effort into reaching them.

This is made evident by the high marks on the restrictive eating habits scale, which signifies that the participants were imposing some dietary restrictions on themselves. Given the fact that the general body image for the participants of this group was highly positive, we conclude that their efforts were successful.

The aforementioned conclusions lead us to designate this second factor as «positive general self-attitude with low weight satisfaction and restrictive eating habits». It should be noted that the participants' propensity to restrict their diet is evident of their deliberate approach towards eating, aimed at reaching and maintaining a desired weight.

The third factor consists of the following variables:

General intensity of psychological defenses (0.980);

Compensation (0.656);

Hypercompensation (0.556);

Regression (0.505)

In this case, the data shows a heightened intensity of a compensatory defense mechanism (compensation), which is often grouped with «identification». Women engaging this mechanism strive to replace their real and perceived flaws by assuming traits, strengths, and behaviors of other people. Such assimilation is done with no prior analysis or personal restructuring and, as a result, they don't tend to become integral parts of the personality.

Multiple sources have claimed that the mechanism of compensation is one of the defenses against the inferiority complex, and it leads individuals to advance their developed traits further and further in order to compensate for a perceived deficiency.

The aforementioned results confirm our suppositions regarding the second factor. Being content with their bodies the participants from this group displayed an acute dissatisfaction with their weight and put in efforts into changing it. By moving towards an ideal self they displayed attempts to compensate their perceived flaws in other areas.

A considerable weight of the regression variable might signify that under the influence of frustrating external factors the participants from this group displayed a propensity to replace subjectively more difficult tasks with easier and more accessible ones. Among possible manifestations of this mechanism's influence is an elevated interest towards food as a means of achieving physical satisfaction.

Getting back to compensation, it should be noted that it remains one of the more positive defensive mechanisms, since it motivates people to regulate their behavior and take steps towards personal development. It is mostly exhibited by more mature individuals, with mature psychological defense mechanisms. 
We designate this third factor as «prevalence of mature psychological defensive mechanisms».

The fourth factor consists of the following variables:

Assessment of own appearance (0.921);

Assessment of own facial features (0.795);

Reflected assessment of appearance (0.769).

In this instance the participants displayed high values in all indices related to positive attitude towards appearance. Participants from this group likely though themselves attractive and had little difficulty communicating within their social circle. With that said, the structure of their self-concept did reveal that they considered their face to be an autonomous element of their appearance. With that in mind, we designate this factor as «favorable self-attitude».

The factor analysis of the data from the $2^{\text {nd }}$ group also revealed 4 factors of SWB.

The first factor consists of the following variables:

General self-attitude (0.787);

Expected attitude from others $(0.720)$;

Self-respect (0.691);

Subjective assessment of facial features (0.685);

Self-interest (0.672);

Body image (- 0.667);

Self-confidence (0.664);

General satisfaction with own appearance (0.619);

Level of despondency (- 0.613);

Subjective assessment of own body (0.610);

Overall body image (- 0.609$)$;

Assessment of own appearance (0.589);

Reflected assessment of appearance (0.587);

Autosympathy (0.580);

Self-understanding (0.554);

Denial (0.513)

In this case the data shows a counterintuitive combination of variables signifying low level of body satisfaction and high self-esteem. This dissonance is due to a defensive mechanism of denial. More than likely, in an effort to get rid of negative emotions related to body dissatisfaction, the participants from this group opted to simply ignore their perceived flaws. Thus, they were able to avoid negative emotions and feelings and maintain high levels of self-respect.

The use of this mechanism is associated with tendencies towards egocentrism, boastfulness, a need to be at the center of attention, and increased sociability. These traits could explain the negative value of despondency. In turn, low despondency might manifest through ostentatious joy, elevated spirits and even euphoria.

With the aforementioned results in mind we designate this factor as «positive self-attitude with positive expected attitude from others, low body satisfaction, and denial of despondency".

The second factor consists of the following variables:

General intensity of psychological defenses (0.954);

Compensation (0.658);

Regression (0.645);

Projection (0.634);

Rationalization (0.587);

Hypercompensation (0.585);

Denial (0.557). 
In this case the participants displayed the use of the whole range of defense mechanisms. Like the first group, they showed high values in hypercompensation, compensation, and regression, but added to that high values in rationalization and denial. It indicates that this category of women simply ignored the existence of their flaws, while searching for excuses for any worrisome behavior.

It should be noted that the participants from this group would come up with excuses for their questionable actions only after the fact. For example, an excuse of «being so hungry one could die» would be used to justify an episode of overindulging in food. Thus the women attempt to present the situation as being out of their control, and the detrimental actions as being the result of external circumstances.

High values in projection indicate that the participants from this group tended to ascribe their flaws to others. Such an attitude leads to attempts to reassert oneself and protect the ego with preemptive aggression. By provoking others, the individual seeks to blame them for her own flaws and interprets their actions through the prism of her own motives. This leads to outward hostility and envy, a tendency to blame others for one's own faults. Pride, selfishness, vindictiveness, resentfulness, a heightened sense of injustice, arrogance, vanity, suspiciousness, jealousy, hostility, stubbornness, intransigence, intolerance of objections the list of socially detrimental traits tied to this psychological mechanism goes on and on.

It is abundantly clear that a mature personality with healthy ways of dealing with conflict is incompatible with projection being the primary defense mechanism. In this regard, we designate this second factor as «prevalence of immature psychological defenses».

The third factor consists of the following variables:

- Subjective assessment of own weight (- 0.729);

- Satisfaction with own weight (- 0.689);

- Body image (0.623);

- Attitude towards eating (0.576).

In this case the participants displayed dissatisfaction with their weight along with a certain level of addiction to eating. The data suggests women in this category tend to overeat and thus gain unwanted weight. However, the overall body image value was relatively high, which might suggest that the actual weight is not the primary factor of body image. We designate this factor «positive overall attitude towards own body with unregulated eating habits".

The fourth factor is weighted by the following variables:

- Self-consistency (0.737);

- General self-attitude (0.530);

- Self-respect (0.594).

In this case, the participants displayed a favorable attitude towards themselves, with confidence in their abilities, capabilities, drive, independence, and the ability to control their own life and understand themselves. We designate this factor as «undifferentiated favorable self-attitude».

Table 2 shows the key differences between the two groups of participants, as revealed by the factor analysis:

Table 2. Factor analysis results

\begin{tabular}{|l|l|}
\hline $\begin{array}{l}\text { Participants with body assessment above } \\
\text { average }\end{array}$ & $\begin{array}{l}\text { Participants with body assessment below } \\
\text { average }\end{array}$ \\
\hline $\begin{array}{l}\text { Positive self-attitude with positive expected } \\
\text { attitude from others }\end{array}$ & $\begin{array}{l}\text { Positive self-attitude with positive expected } \\
\text { attitude from others, low bodily satisfaction, and } \\
\text { denial of despondency }\end{array}$ \\
\hline $\begin{array}{l}\text { Positive general self-attitude with low weight } \\
\text { satisfaction and restrictive eating habits }\end{array}$ & $\begin{array}{l}\text { Positive overall attitude towards own body with } \\
\text { unregulated eating habits }\end{array}$ \\
\hline
\end{tabular}




\begin{tabular}{|l|l|}
\hline $\begin{array}{l}\text { Prevalence of mature psychological defensive } \\
\text { mechanisms }\end{array}$ & Prevalence of immature psychological defenses \\
\hline Favorable self-attitude & Undifferentiated favorable self-attitude \\
\hline
\end{tabular}

In summation, the data definitively shows that the body image as a structural component of the SWB determines not only the specifics of the self-image in adolescent girls, but also the range of their coping strategies.

\section{Conclusion}

The following goals were set and achieved in the course of this study:

1. We conducted a comprehensive analysis of the existing research into subjective wellbeing, body image, their structural components, and the relationship between them.

2. We conducted an empirical study of the structural components of body image as a component of SWB in young women.

The data analysis was done using Spearman correlation analysis and factor analysis.

The results showed that the subjective assessment of one's own body has tremendous influence on the elements of one's personality.

Using factor analysis, we detailed the psychological features of women with positive and negative attitudes towards their bodies. The first group comprised of four factors, designated as «individuals with high self-esteem», «individuals striving for perfection», «socially mature individuals», and «individuals with positive attitudes towards their bodies». The second group comprised of four factors designated as «individuals with inadequate selfesteem», «socially immature individuals», «individuals free of insecurities», and «selfconsistent individuals». We determined and described the contributing factors for every one of the groups as well as their intensity, thus deepening the understanding of the differences between them.

3. We conducted an empirical study of the adaptive strategies employed by women with different attitudes towards their bodies. In particular, we analyzed the frequency of use for eight psychological defensive mechanisms and their overall intensity.

Thus, we successfully achieved the goals of the study and proved the initial hypothesis stating that body image - being a structural component of SWB in adolescent girls - does display a negative correlation with such negative personal characteristics as despondency, guilt, and frustration, and a positive correlation with self-understanding, self-respect, and self-consistency among others.

\section{References}

1. G. S. Abramova, Vozrastnaya psikhologiya, Developmental psychology: A study guide for university students (Akademicheskiy Proekt publ.; Yekaterinburg, Delovaya kniga publ., Moscow, 2000)

2. E. V. Belugina, Attitude towards one's appearance in mid-life period, $\mathrm{PhD}$ Thesis, (Rostov-on-Don, 2003)

3. L.I. Vasserman, O.F. Yeryshev, E.B. Klubova, N.N. Petrova, I.G. Bespalko, M.A. Berebin, M.I. Saveleva, L.M. Taukenova, A.V. Shtrakhova, T.A. Aristova, I.M. Osadchiy, Psychological evaluation of the lifestyle index, Guide for psychologists and doctors (Psychoneurological Research Institute, St.Petersburg, 2003)

4. A. A. Gavrilenko, Concept of the psysical self as a component of the self-concept, $\mathrm{PhD}$ Thesis, (Moscow, 2009) 
5. K.V. Ivanova, Features of self-conciousness in women dissatistied with their bodies: the case of women dissatisfied with their weight, PhD Thesis, (Moscow, 2009)

6. A.V. Ivashchenko, N.B. Karabushchenko, T.S. Pilishvili, T.V. Chykvadze, Psikhologicheskii Zhurnal 3(17), 225-228 (2016)

7. K.V. Lobin, Structure of self-image in obese women (as per the goals of psychotherapy), $\mathrm{PhD}$ Thesis, (Saint-Petersburg, 2006)

8. I.G. Malkina-Pykh, Therapy of eating habits (Eksmo publ., Moscow, 2005)

9. G.G. Ovchinnikova, Socially-psychological adaptation as factor of self-image formation in adolescents, $\mathrm{PhD}$ Thesis, (Moscow, 1997)

10. S.R. Panteleev, Methodology for self-attitude study (Smysl publ., Moscow, 1993)

11. E.A. Petrova, D.A. Smyslov, Individual social psychology. Study guide for students (RITS AIM publ., Moscow, 2008)

12. T.S. Pilishvili, The Open Psychology Journal 1(10), 11-18 2017 doi: 10.2174/1874350101710010011

13. T.S. Pilishvili, A.L. Danilova, Revista Espacios Venezuela 39(30), 13 (2018)

14. T. Pilishvili, A. Danilova, Revista Espacios Venezuela 40(26), 19 (2019)

15. T.S. Pilisvhili, E.F. Koyanongo, Psychology in Russia: State of the Art 1(9), 84-97 (2016) doi: 10.11621/pir.2016.0106

16. T. Pilishvili, N. Karabushchenko, E. Magomedova, R. Russel, I. Medvedeva Revista Espacios Venezuela 39(30), 13 (2018)

17. Yu.L. Savchikova, Psychological issues in women struggling with weight, $\mathrm{PhD}$ Thesis, (Saint-Petersburg, 2005)

18. O.A. Skugarevskiy, S.V. Sivukha, Psychology 4, 40-48 (2006)

19. Ye.B. Stankovskaya, Structure and types of body-related aspect of self-attitude, $\mathrm{PhD}$ Thesis, (Moscow, 2011)

20. A.G. Cherkashina, Concept of physical self in self-attitude of adolescent girls, $\mathrm{PhD}$ Thesis, (Samara, 2004)

21. E. Erikson, Identity: adolescence and crisis (Progress publ., Moscow, 1996)

22. D.M. Ackard, J.K. Croll, \& A. Kearney-Cooke, Journal of Psychosomatic Research 52, 129-136 (2002)

23. C. Bjornskov, Social Science and Medicine 66, 1750- 1759 (2008)

24. A. Boissy, G. Manteuffel, M.B. Jensen, R.O. Moe, B. Spruijt, L.J. Keeling, et al., Physiology \& Behavior. 92, 375-397 (2007)

25. A. Borges, Gaspar de Matos M. and J. Diniz, The Spanish Journal of Psychology 16, (2013). doi.org/10.1017/sjp.2013.24 Published online: 07 June 2013

26. J. Cattarin, K. Thompson, C. Thomas, and R. Williams, Journal of Social and Clinical Psychology 19(2), 220-239 (2000)

27. Y. Chida, \& A. Steptoe, Psychosomatic Medicine 70, 741-756 (2008)

28. S. Cohen, C.M. Alper, W.J. Doyle, J.J. Treanor, \& R.B. Turner, Psychosomatic Medicine 68, 809-815 (2006)

29. Daniel Clay V. L., Journal of Research on Adolescence 451 - 477 (2005) doi:10.1111/j.1532-7795.2005.00107.x

30. K.W. Davidson, E. Mostofsky, \& W. Whang, European Heart Journal 31, 1065-1070 (2010) 